\title{
La renuncia de área como medio de saneamiento de área, linderos y medidas perimétricas de predios urbanos
}

The renunciation of perimeter area as a means of sanitation of the area, boundaries, and perimeter measurements of urban properties

0 (이

JORGE LUIS GONZALES LOLI

Pontificia Universidad Católica del Perú

(Lima, Perú)

Contacto: jlgonzales@pucp.pe

https://orcid.org/0000-0003-4916-4076

\section{RESUMEN}

En el presente artículo se efectúa un análisis a la regulación, la operatividad y la eficiencia del procedimiento registral de «renuncia de área» como medio de saneamiento incorporado a través del Pleno CIX del Tribunal Registral de la Superintendencia Nacional de los Registros Públicos. Se destacan aspectos doctrinales y jurisprudenciales en torno a su reglamentación y utilidad práctica, con la finalidad de evaluar su funcionalidad y la posible necesidad de mejoras normativas. Previamente, para lograr un mejor entendimiento del tema planteado, enunciaremos los aspectos más 
relevantes de los demás procedimientos de saneamiento de áreas, linderos y medidas perimétricas que, en vía judicial, notarial y registral, son aplicables a los predios urbanos.

Palabras clave: renuncia de área; linderos; medidas perimétricas; saneamiento.

\section{ABSTRACT}

This article analyzes the regulation, operability, and efficiency of the registration procedure of «renunciation of area» as sanitation means incorporated through the CIX Plenary Session of the Registry Court of the National Superintendence of Public Registries. Doctrinal and jurisprudential aspects are highlighted regarding its regulation and practical utility, to evaluate its functionality and the possible need for regulatory enhancements. Previously, to achieve a better understanding of the issue, we will describe the most relevant aspects of the other sanitation procedures of areas, borders, and perimetric measurements that apply to urban properties in judicial, notarial, and registry proceedings.

Key words: area renunciation; borders; perimeter measurements; sanitation.

Recibido: 17/05/2021 Aceptado: 25/05/2021

\section{CONCEPTO DE SANEAMIENTO DE ÁREA, LINDEROS Y MEDIDAS PERIMÉTRICAS}

De acuerdo con nuestra normatividad, esta figura comprende tanto la determinación como la rectificación área, linderos y medidas perimétricas, cuando no se encuentren establecidos o en el supuesto de que existan discrepancias entre la realidad y lo inscrito en el registro. Por consiguiente, a diferencia de otros mecanismos como 
la accesión, apropiación o prescripción adquisitiva de dominio, no implica una variación o modificación en la realidad física del predio. Una vez hecha esta precisión, resulta conveniente revisar algunos conceptos doctrinales y jurisprudenciales sobre el tema.

\subsection{Conceptos doctrinales}

Gunther Gonzales Barrón (2002) sostiene que

el presupuesto teórico de la rectificación de área es el error de medición, pese a que los linderos se pudiesen encontrar delimitados con razonable certeza, lo que implica una discrepancia entre la dimensión real del predio y la información del registro. Por tanto, la rectificación de área no sirve para invadir la finca vecina, o matricular una porción de terreno no inscrita, o para regularizar transferencias de franjas colindantes, o reconocer el aumento de área por virtud de accesiones, o para hacer deslinde (p. 511).

Según Rosario Guerra Macedo (2014):

la rectificación de área tiene como finalidad eliminar la inexactitud publicada por el Registro. Quiere decir que la realidad registral del predio discrepa de la realidad física. El área publicitada del predio es mayor o menor o con linderos total o parcialmente diferentes. Para corregir esa inexactitud hay varios procedimientos establecidos normativamente. La trascendencia de estos medios para eliminar la inexactitud registral radica en el hecho de que la partida registral refleja una descripción material del predio distinta a la existente, se trata por tanto de hacer concordar lo inscrito con la realidad objetiva del predio existente (p. 343).

Para Becerra, Samillan y Esquivel (2019):

entonces, queda claro que la rectificación de la descripción física de un predio, en cualquiera de sus modalidades solo busca eliminar una inexactitud a fin de publicitar las dimensiones físicas que 
siempre tuvo un predio sin aumentar ni disminuir su cabida real, pues lo que se rectifica es el dato numérico (formal) que puede haberse consignado en mayor o menor medida al área real (p. 39).

De acuerdo con Silva (2009):

la rectificación no tiene por objeto la incorporación a la partida registral de una porción de un predio adyacente que fue adquirido a través de un título transmisivo de dominio no inscrito o que fue usurpado. Sin embargo, como excepción a dicha regla, afirma que es admisible la rectificación de área por la incorporación de una porción de un predio a otro como consecuencia de la accesión, tal como lo ha establecido el Tribunal Registral de la SUNARP en la Resolución N 015-2007-SUNARP-TR-L del 18 de enero de 2007 (p. 278).

\subsection{Conceptos jurisprudenciales}

Para el Tribunal Registral (2016c):

el saneamiento de áreas, linderos o medidas perimétricas es un mecanismo para eliminar una inexactitud registral. No ocurre que la finca crezca, se modifique o reduzca su extensión, lo que sucede es que registralmente, la realidad física aparece descrita en el Registro de modo diferente, por lo cual es necesario adecuar la información del Registro a la realidad. Precisamente porque existe la posibilidad de que la realidad física sea reflejada defectuosamente por el Registro, existe legislación que regula diversas formas de rectificación de área y linderos (p. 9).

Asimismo, "mediante la rectificación de las características físicas de un predio no se incorpora nueva superficie al predio inscrito. Dicho proceso solo busca eliminar una inexactitud registral, expresando en su verdadera dimensión lo ya existente» (Tribunal Registral, 2007c, p. 1) y «la rectificación de las características físicas de un predio es un instrumento para eliminar una inexactitud registral, pues la finca 
(cuyas características físicas no han variado y por tanto no ha crecido, o se ha modificado o reducido) aparece descrita erróneamente en el Registro» (Tribunal Registral, 2016a, p. 1).

De lo expuesto, queda claro que el procedimiento de rectificación de área, linderos y medidas perimétricas no tiene como finalidad aumentar o reducir el área del predio registrado, sino únicamente hacer que coincidan la publicidad registral con la realidad, eliminando de esta forma la inexactitud. Corresponde que los funcionarios que tienen a su cargo dicho procedimiento cuiden que este no se desnaturalice, ya que cualquier cambio en los datos de hecho de un predio constituye un riesgo para los demás titulares registrales, en especial los propietarios de los predios colindantes. En tal sentido, como el registrador no realiza una labor de constatación in situ, sino que solo califica documentos, aquel no será responsable por la mala praxis que se le pueda dar a dicho mecanismo registral. En suma, el límite de la rectificación (o determinación) es el respeto a la propiedad de los demás titulares de derechos inscritos, para que no puedan ser afectados por esta clase de procedimientos. Ello implica necesarias exigencias técnicas y legales aplicables, de distinta manera y rigor, a los procedimientos de saneamiento de áreas, linderos y medidas perimétricas.

\section{EL SANEAMIENTO DE ÁREA, LINDEROS Y MEDIDAS PERIMÉTRICAS EN SEDE JUDICIAL}

Este mecanismo, que guarda relación con la acción conocida como deslinde, tiene su sustento y regulación en nuestro Código Civil (CC) y Código Procesal Civil (CPC). De una parte, el artículo 966 del CC faculta a todo propietario de un bien inmueble a deslindar su propiedad, previa citación de los dueños o poseedores de los predios colindantes, al indicar que: «El propietario de un predio puede obligar a los vecinos, sean propietarios o poseedores, al 
deslinde y al amojonamiento». Asimismo, el artículo 504 del CPC, además de establecer que se debe seguir el trámite por la vía del proceso abreviado, regulado por el Título II del Libro de la Sección Quinta del CPC, legitima a quien deberá presentar la demanda, y son facultados para ello tanto el propietario como el poseedor del predio, al contemplar en su numeral 3 la demanda que formula «el propietario o poseedor para que se rectifiquen el área o los linderos, o para que se limiten estos mediante deslinde».

Con lo anterior, el predio que se va a rectificar, así como el predio colindante, pueden estar procesalmente representados tanto por los propietarios como por los poseedores de estos. En el caso de que el proceso sea iniciado por una persona que solo tiene posesión y no titularidad dominical del predio a rectificar, se plantean dificultades para el acceso de lo resuelto a la publicidad registral, pues una de las exigencias en la calificación registral de la inscripción de la rectificación es, precisamente, que el demandante tenga derechos inscritos en el registro de predios. Así, afirma Guerra Macedo (2016) que:

El hecho que el poseedor esté legitimado para iniciar el proceso de rectificación de áreas y linderos resulta poco práctico pues se carece de forma alguna en el que un proceso iniciado por el poseedor pueda acceder al Registro, salvo reiteración del juez, puesto que no existiría adecuación con el antecedente registral (p. 348).

Otro aspecto que debe tenerse en cuenta es que, de manera necesaria, debe acudirse a este mecanismo judicial si surge oposición durante el trámite del procedimiento no contencioso de competencia notarial de rectificación de área, linderos y medidas perimétricas, o si en aquel se verifica que existe superposición de las áreas o los linderos. En general, cuando el saneamiento de área, linderos y medidas perimétricas no pueda efectuarse por alguno de los demás medios notariales y registrales vigentes, siempre podrá acudirse al proceso judicial, que no se encuentra tan limitado por 
exigencias o requisitos como los otros mecanismos, que no deben resolver sobre los derechos sustantivos de los propietarios.

\subsection{Reglas generales}

\subsubsection{Juez competente}

Se determina conforme al artículo 488 del Texto Único Ordenado del CPC, que señala que los juzgados de paz letrados son competentes cuando la cuantía de la pretensión es mayor a 100 y hasta 500 unidades de referencia procesal ${ }^{1}$ (URP). Mientras que los jueces civiles son competentes cuando se superen las 500 URP, o no sea aplicable la cuantía; es el caso de la rectificación de área, linderos y medidas perimétricas, que se tramita ante los juzgados civiles.

\subsubsection{Procedimiento}

Los plazos de primera instancia establecidos en el CPC son los siguientes:

\section{Tabla 1}

Plazos del procedimiento abreviado

\begin{tabular}{lcc}
\hline \multicolumn{1}{c}{ Acto procesal } & $\begin{array}{c}\text { Tiempo } \\
\text { (días) }\end{array}$ & $\begin{array}{c}\text { Artículo } \\
\text { (CPC) }\end{array}$ \\
\hline Subsanar de acuerdo con el auto de inadmisibilidad de la demanda & 10 & 426 \\
\hline Emplazamiento de la demanda & 30 o 45 & 435 y 492 \\
\hline Interponer tachas u oposiciones a las pruebas & 3 & 491.1 \\
\hline Absolver tachas u oposiciones & 3 & 491.2 \\
\hline Interponer excepciones o defensas previas & $5^{*}$ & 491.3 \\
\hline Absolver el traslado de las excepciones o defensas previas & 5 & 491.4 \\
\hline Contestar la demanda $^{* *}$ & 10 & 491.5 \\
\hline
\end{tabular}

1 Para el 2021, se fija el valor de la unidad de referencia procesal (URP) en cuatrocientos cuarenta y 00/100 soles (S/ 440.00) (Gaceta Jurídica, 2021, párr. 2). 


\begin{tabular}{lcc}
\hline $\begin{array}{l}\text { Ofrecimiento de medios probatorios si en la contestación se } \\
\text { invocan hechos no expuestos en la demanda }\end{array}$ & 5 & 491.6 \\
\hline Saneamiento & 10 & 491.8 \\
\hline Fijación de puntos controvertidos & 3 & 468 \\
\hline Realización de la audiencia de pruebas & 20 & 491.9 \\
\hline Audiencia especial y complementaria (de ser el caso) & 5 & 491.10 \\
\hline Alegatos & 5 & 212 \\
\hline Sentencia & 25 & 491.11 \\
\hline
\end{tabular}

* Contados desde la notificación de la demanda o de la reconvención.

** Improcedencia de la reconvención: según lo establece el artículo 490 del CPC (en este proceso el demandado no podrá contrademandar al demandante).

\subsection{Otros asuntos releuantes}

\subsubsection{Notificaciones y problemas operatiuos}

En este proceso, por disposición del artículo 506 del CPC, pese a que se conozca el nombre y el domicilio del demandado o los demandados y, en su caso, de los colindantes, en el auto admisorio de la demanda el juez dispondrá que el extracto de esta se publique tres veces, con un intervalo de tres días, mediante edictos. En caso el bien sub litis sea un predio rústico, y el demandado, indeterminado, o incierto, o con domicilio o residencia ignorado, en el emplazamiento, además del edicto, se deberá efectuar la notificación por radiodifusión cinco días consecutivos, tal como lo indica el último párrafo del artículo mencionado.

Además, según lo dispone el artículo 507, en los casos en que el demandado sea indeterminado, o incierto, o su domicilio o residencia sea ignorado, o cuando el emplazado haya sido declarado en rebeldía, se solicitará dictamen del Ministerio Público antes de pronunciar sentencia. Este será expedido dentro de diez días, bajo responsabilidad. 
Es pertinente indicar que si bien el procedimiento judicial, por su propia naturaleza, tiene una amplitud mayor a los procedimientos de saneamiento notariales y registrales, puesto que abarca todos los tipos de predios (rústicos y urbanos) y de defectos (falta delimitación o inexactitud), con existencia de eventuales conflictos (con superposición con los predios colindantes o sin ella) o no, es frecuente que las autoridades jurisdiccionales no presten demasiada atención a las titularidades registrales ni a los aspectos técnicos descriptivos del predio y, menos aún, a la base gráfica registral (delimitación georeferenciada de los predios inscritos, sobre la base de los asientos registrales y los títulos archivados que dieron lugar a las inscripciones). Esto origina que, aun en los casos que obtienen un pronunciamiento judicial definitivo, después de largos y complicados trámites, lo resuelto no puede acceder a la publicidad registral; o que, al inscribirse por mandato reiterativo de la autoridad judicial, más que corregir o mejorar la información registral, se generan nuevas inexactitudes y controversias que, por ejemplo, pueden afectar derechos de terceros colindantes que no han sido emplazados en el proceso judicial.

\subsubsection{Demora de los procesos judiciales}

Nuestro sistema de justicia, a través de sus órganos jurisdiccionales, se ve enfrentado a esta problemática generada fundamentalmente por la excesiva carga procesal. Como prueba nos permitimos poner a consideración los siguientes estudios:

\subsubsection{Procesos sumarísimos}

En su informe sobre la justicia en el Perú, Gaceta Jurídica (2015, pp. 33-34) señala que uno de los principales factores de la morosidad judicial es el retraso en la entrega de las notificaciones judiciales. Asimismo, se indica que un proceso de desalojo por ocupación precaria, que se tramita en la vía sumarísima, dura en promedio cuatro años y tres meses, a pesar de que debería durar solo cinco 
meses, de conformidad con las normas del CPC. En dicho informe se sostiene que el cálculo del plazo del proceso de desalojo por ocupación precaria excluye el tiempo de ejecución de la sentencia, por lo que el plazo legal y el plazo real son mayores si se considera el tiempo de ejecución.

Según el informe del Banco Mundial (2020), que evaluó, entre otros aspectos, cuánto demora en el Perú hacer cumplir un contrato en sede judicial mediante proceso sumarísimo, «es más fácil en los juzgados de Huancayo y más difícil en los del Callao. Mientras en Huancayo los casos tardan alrededor de 22 meses, en el Callao duran hasta 2.5 años, principalmente por la demora en la notificación de las demandas y la ejecución de sentencias» (p. 73). Si el proceso sumarísimo tiene menores trámites y plazos procesales que el proceso abreviado aplicable a la rectificación área, linderos y medidas perimétricas, resulta evidente que estos últimos tendrán una duración sustancialmente mayor.

\subsubsection{Un ejemplo respecto de un proceso de rectificación de área y linderos}

Como se observa en el Expediente n. ${ }^{\circ}$ 28883-2018-0-5001-SUDC-01, la Sala de Derecho Constitucional y Social de la Corte Suprema de Justicia, con fecha 14 de noviembre de 2020, declaró improcedente esta casación debido a que dicha sala no es competente para conocer causas sobre temas rurales, por lo que dispuso que se remita a la mesa de partes de la Sala Civil Permanente y Transitoria de la Corte Suprema. Es decir, el proceso aún continuará. No obstante, en el siguiente reporte del expediente de la Corte Suprema de Justicia (2018), podemos verificar desde cuándo se inició ese proceso. 


\section{Gráfico 1}

\section{Consulta a expediente del Poder Judicial}

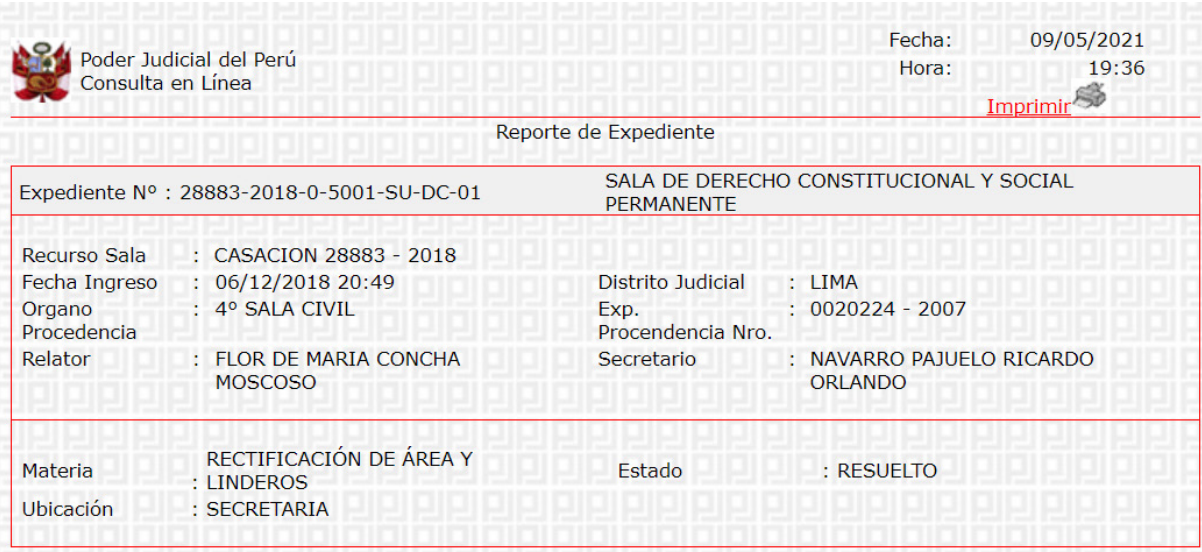

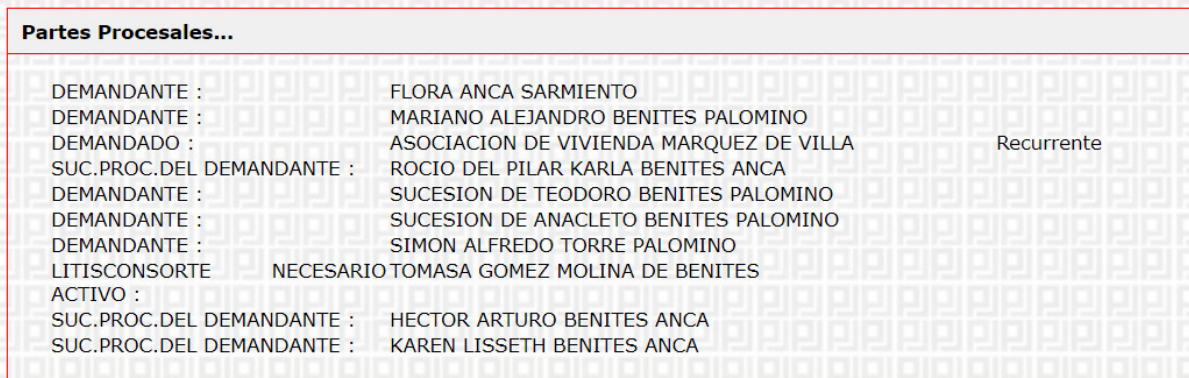

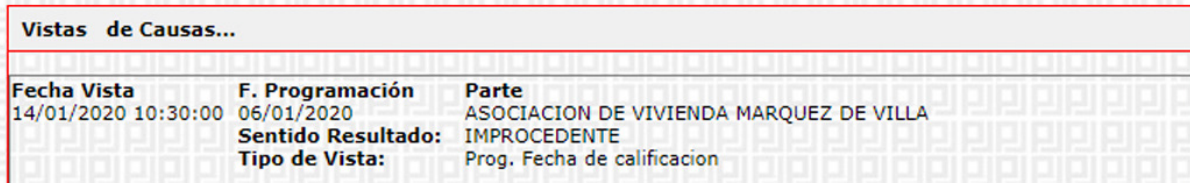

El expediente que motivó dicha casación es el n. ${ }^{\circ}$ 0020224-2007. Para conocer la fecha de inicio del proceso judicial, hemos ingresado a las consultas de expedientes judiciales del Poder Judicial. Al encontrar el expediente, podemos observar que dicho proceso se inició el 11 de mayo de 2007, tal como lo muestra el siguiente gráfico: 


\section{Gráfico 2}

\section{Consulta a expediente del Poder Judicial ${ }^{2}$}

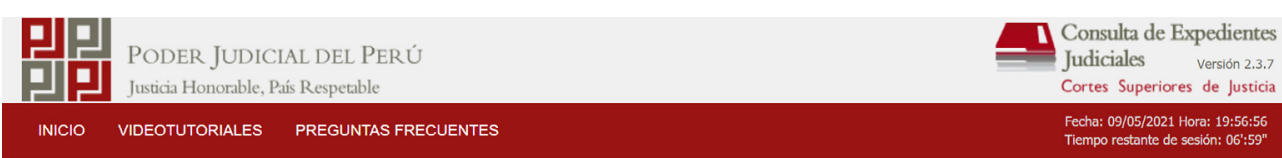

\section{REPORTE DE EXPEDIENTE}
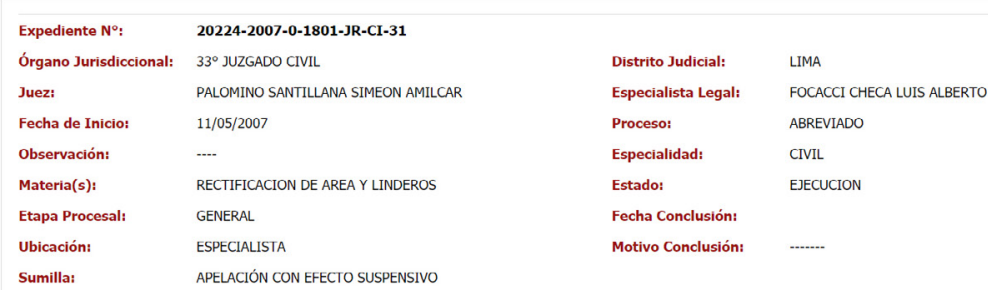

De lo expresado se concluye que, a la fecha, dicho proceso tiene más de catorce años en litigio y aún no se ha emitido una sentencia definitiva sobre el fondo. Con todo lo expuesto, consideramos que la demora de los procesos judiciales constituye una sustancial desventaja en relación con cualquiera de los procedimientos extrajudiciales de rectificación de áreas, linderos y medidas perimétricas vigentes. Si bien no se cuenta con estadísticas suficientes sobre la duración "promedio» de estos procedimientos, podemos afirmar que lo normal es que no concluyan su trámite en menos de cuatro años, salvo casos muy aislados o excepcionales.

Por otra parte, en cuanto al número de demandas presentadas al Poder Judicial y aquellas que han sido declaradas fundadas, para corroborar nuestros datos, mediante solicitud de acceso a la información, pedimos al Poder Judicial que nos proporcionara estadísticas respecto de las siguientes interrogantes: ¿a nivel nacional, cuántas demandas de rectificación de área, linderos (deslinde) y medidas perimétricas han sido interpuestas ante el Poder Judicial

2 Para observar el reporte de expediente, utilice la plataforma de búsqueda de los expedientes en https://cej.pj.gob.pe/cej/forms/busquedaform.html. 
durante cada uno de los años comprendidos entre el 2014 y el 2018? ¿Cuántas han sido fundadas? El Poder Judicial, en el Informe n. ${ }^{\circ}$ 000043-2020-AABD-SPAP-GI-GG, del 27 de enero de 2020, adjuntó el reporte de respuesta a nuestras preguntas, el cual hemos procesado en la siguiente tabla de elaboración propia:

\section{Tabla 2}

Demandas de rectificación de área y linderos (2014-2018)

\begin{tabular}{|c|c|c|c|c|c|c|c|c|}
\hline & 2014 & 2015 & 2016 & 2017 & 2018 & Total & Fundadas & $\%$ \\
\hline Amazonas & 3 & 1 & 10 & 5 & 11 & 30 & 5 & $17 \%$ \\
\hline Áncash & 11 & 13 & 19 & 19 & 16 & 78 & 5 & $6 \%$ \\
\hline Apurímac & 5 & 13 & 25 & 6 & 14 & 63 & 6 & $10 \%$ \\
\hline Arequipa & 8 & 26 & 12 & 21 & 18 & 85 & 15 & $18 \%$ \\
\hline Ayacucho & 14 & 11 & 5 & 15 & 5 & 50 & 6 & $12 \%$ \\
\hline Cajamarca & 5 & 26 & 29 & 30 & 38 & 128 & 16 & $13 \%$ \\
\hline Callao & 0 & 0 & 4 & 0 & 0 & 4 & 0 & $0 \%$ \\
\hline Cañete & 2 & 1 & 2 & 1 & 4 & 10 & 2 & $20 \%$ \\
\hline Cusco & 47 & 51 & 50 & 52 & 41 & 241 & 50 & $21 \%$ \\
\hline Del Santa & 6 & 16 & 11 & 9 & 3 & 45 & 4 & $9 \%$ \\
\hline Huancavelica & 5 & 4 & 1 & 3 & 2 & 15 & 8 & $53 \%$ \\
\hline Huánuco & 49 & 55 & 22 & 26 & 14 & 166 & 22 & $13 \%$ \\
\hline Huaura & 12 & 14 & 5 & 10 & 15 & 56 & 6 & $11 \%$ \\
\hline Ica & 16 & 38 & 19 & 21 & 22 & 116 & 21 & $18 \%$ \\
\hline Junín & 7 & 28 & 17 & 19 & 16 & 87 & 8 & $9 \%$ \\
\hline La Libertad & 14 & 35 & 22 & 24 & 19 & 114 & 17 & $15 \%$ \\
\hline Lambayeque & 34 & 33 & 27 & 23 & 39 & 156 & 16 & $10 \%$ \\
\hline Lima & 23 & 9 & 13 & 6 & 10 & 61 & 13 & $21 \%$ \\
\hline Lima Este & 18 & 8 & 6 & 11 & 7 & 50 & 3 & $6 \%$ \\
\hline Lima Norte & 11 & 11 & 7 & 8 & 10 & 47 & 2 & $4 \%$ \\
\hline Lima Sur & 2 & 5 & 4 & 4 & 7 & 22 & 1 & $5 \%$ \\
\hline Loreto & 2 & 6 & 1 & 1 & 2 & 12 & 1 & $8 \%$ \\
\hline Madre de Dios & 4 & 5 & 2 & 2 & 4 & 17 & 0 & $0 \%$ \\
\hline Moquegua & 5 & 4 & 13 & 21 & 5 & 48 & 6 & $13 \%$ \\
\hline
\end{tabular}




\begin{tabular}{ccccccccc}
\hline Pasco & 1 & 0 & 0 & 0 & 0 & 1 & 0 & $0 \%$ \\
\hline Piura & 4 & 15 & 8 & 7 & 8 & 42 & 4 & $10 \%$ \\
\hline Puno & 6 & 7 & 5 & 1 & 3 & 22 & 2 & $9 \%$ \\
\hline San Martín & 16 & 16 & 21 & 15 & 19 & 87 & 10 & $11 \%$ \\
\hline Selva Central & 0 & 0 & 0 & 0 & 7 & 7 & 0 & $0 \%$ \\
\hline Sullana & 8 & 9 & 0 & 2 & 3 & 22 & 0 & $0 \%$ \\
\hline Tacna & 14 & 24 & 18 & 22 & 8 & 86 & 6 & $7 \%$ \\
\hline Tumbes & 3 & 5 & 3 & 2 & 3 & 16 & 3 & $19 \%$ \\
\hline Ucayali & 0 & 0 & 0 & 0 & 2 & 2 & 0 & $0 \%$ \\
\hline Ventanilla & 0 & 1 & 1 & 1 & 0 & 3 & 0 & $0 \%$ \\
\hline TOTAL & $\mathbf{3 5 5}$ & $\mathbf{4 9 0}$ & $\mathbf{3 8 2}$ & $\mathbf{3 8 7}$ & $\mathbf{3 7 5}$ & 1989 & 258 & $13 \%$ \\
\hline
\end{tabular}

Verificamos que aquellas demandas declaradas fundadas entre el 2014 y el 2018 representan un porcentaje que no llega siquiera al $15 \%$ de las presentadas, como puede apreciarse a continuación:

\section{Tabla 3}

Relación de demandas de rectificación de área, linderos y medidas perimétricas presentadas y fundadas en el período 2014-2018 en el Poder Judicial

\begin{tabular}{lcc}
\hline $\begin{array}{l}\text { Demandas de rectificación de área, linderos y medidas } \\
\text { perimétricas }\end{array}$ & 1989 & $100 \%$ \\
\hline Sentencias fundadas & 258 & $13.0 \%$ \\
\hline
\end{tabular}

Si se considera que los predios inscritos que tienen deficiencias en su delimitación y en su concordancia con lo registrado pueden calcularse en varios millones, y que en cinco años judiciales se tramitaron menos de 2000 demandas, con las demoras en la tramitación y el escaso número de pronunciamientos favorables, podemos afirmar que, en tanto no se supere este problema, es necesario analizar la posibilidad de mejorar la regulación y eficiencia de los mecanismos extrajudiciales registrales y notariales 
existentes para responder a las necesidades de la colectividad. Evidentemente, los medios extrajudiciales no serán aplicables a los casos en que la determinación o rectificación de área, linderos y medidas perimétricas pueda afectar los derechos de propiedad de los titulares de los predios. En todo caso, a partir de nuestra experiencia personal en la función notarial y registral, podemos afirmar que son minoría. En la práctica, la necesidad de determinación o rectificación de área, linderos y medidas perimétricas de predios inscritos no implica, excepto en muy pocos casos, la existencia de conflictos de titularidades, sino que estos se originan, esencialmente, en la falta de una verdadera base geográfica en las inscripciones del registro de predios, la inexistencia de un verdadero catastro predial y la simplicidad de los medios inmatriculatorios que tuvo el registro de propiedad inmueble desde su creación casi a finales del siglo XX.

\section{LOS MEDIOS NOTARIALES Y REGISTRALES DE SANEAMIENTO DE ÁREA, LINDEROS Y MEDIDAS PERIMÉTRICAS}

Para el desarrollo de este tema, hemos resumido, en forma esquemática, las principales características de cada uno de los mecanismos extrajudiciales vigentes de saneamiento de áreas, linderos y medidas perimétricas, tanto de la vía notarial como de la registral, con la excepción de la renuncia de área, la cual abordaremos posteriormente dado que se trata del tema central del presente artículo. Cabe mencionar que los mecanismos notariales se encuentran regulados en el artículo 13 de la Ley n. 27333 y que los mecanismos registrales se derivan de los precedentes de observancia obligatorios aprobados por diversas sesiones plenarias del Tribunal Registral de la SUNARP. 


\title{
3.1. Procedimiento notarial de mutuo acuerdo
}

\author{
Tabla 4
}

\section{Procedimiento notarial. Mutuo acuerdo mediante escritura pública}

Normativa «Cuando sea necesario determinar el área, linderos y medidas perimétricas del terreno, o cuando existan discrepancias entre el área real del terreno, sus medidas perimétricas y/o linderos, con los que figuren en la partida registral del predio, estas podrán determinarse o rectificarse [...]: a) Por mutuo acuerdo: [...] Mediante escritura pública suscrita por el propietario del predio y los propietarios de todos los predios colindantes, en la que estos últimos manifiesten su conformidad con el área, medidas perimétricas y/o linderos, según corresponda» (Congreso de la República, 2000, art. 13.1).

Presupuestos - Acuerdo entre el propietario o los propietarios del bien y los colindantes, aun cuando estos no se encuentren potencialmente afectados.

- En caso se involucren áreas destinadas a vías públicas, el organismo competente para intervenir será la municipalidad provincial, es suficiente que vise los planos para manifestar su consentimiento con la rectificación.

- Puede darse aun cuando exista superposición con predio inscrito, pero deberán modificarse el área, los linderos y las medidas perimétricas de todos los predios involucrados en la superposición.

- «A efectos de realizar el área, linderos y/o medidas perimétricas de un predio por mutuo acuerdo, no se requerirá que los predios colindantes se encuentren inmatriculados» (Tribunal Registral, s. f., p. 48).

Trámite - Acuerdo o convenio entre las partes.

- Presentación de planos y memoria descriptiva (la Ley n. 27333 no menciona cuál debe ser la formalidad de esta documentación técnica).

- Formalización por escritura pública (esta modalidad no constituye propiamente un proceso ante el notario, sino la expresión de la voluntad de los propietarios).

- El notario no constata ni verifica la veracidad material de lo expresado en el documento objeto de formalización, ni efectúa trámites procesales ni emplazamientos diferentes de la misma elevación a escritura pública.

- Corresponde a la instancia registral la comprobación de los antecedentes registrales y, cuando corresponda, la suficiencia y vigencia de la representación, tanto en el caso de apoderamientos voluntarios como cuando corresponde a representantes legales u orgánicos para permitir su acceso a la publicidad registral. 
- No debería requerir presentación de planos visados o código único catastral.

- No requiere verificación notarial del predio.

- Procede la rectificación pese a que el Área de Catastro del Registro de Predios no puede determinar la existencia de superposición.

- Procede rectificar aunque exista superposición con predios colindantes, pero siempre que se rectifiquen los predios de los colindantes.

- Jurisprudencialmente puede aplicarse tanto a predios urbanos como rústicos.

Desventajas - Requiere la intervención notarial del propietario del bien a rectificar y de todos los colindantes. Esta es la principal limitación.

- Si bien no debería requerir la presentación de plano catastral ni visado municipal, la jurisprudencia registral no es clara sobre esa exigencia.

- Puede permitirse la incorporación indebida de áreas no inmatriculadas cuya titularidad se presume a favor del Estado, conforme al artículo 23 de la Ley n..$^{\circ} 29151$.

- Existe discrepancia en la jurisprudencia acerca de si los planos y la memoria descriptiva requieren visación por parte de la municipalidad o no.

\subsection{Procedimiento notarial. Asunto no contencioso}

\section{Tabla 5}

\section{Procedimiento notarial. Asunto no contencioso de competencia notarial}

Normativa

«Se podrá tramitar como un asunto no contencioso de competencia notarial, según los procedimientos a los que se refieren los Artículos 504 y siguientes del Código Procesal Civil, en lo que sea aplicable, siempre y cuando el área real del predio sea igual o inferior a la registrada en la partida. Cuando el área real es superior a la registrada procederá este trámite siempre y cuando exista una certificación registral de que la mayor área no se superpone a otra registrada. Este procedimiento se tramita de conformidad con lo establecido en el Reglamento de la Ley № 27157» (Congreso de la República, 2000, art. 13.1). 


\begin{abstract}
Presupuestos - Que el área real del predio sea igual o inferior a la registrada en la partida. En caso sea superior, procede siempre y cuando exista una certificación registral de que la mayor área no se superpone a otra registrada.

- Ausencia de superposición de partidas (Tribunal Registral, s. f.).

- «Si el área de catastro informa que no es posible verificar si el predio se superpone o no con los predios colindantes inscritos, resulta procedente [el trámite]» (Tribunal Registral, s. f., p. 54).

- «No impide la inscripción de la rectificación o determinación del área, linderos o medidas perimétricas de un predio que la Oficina de Catastro informe que está imposibilitada de establecer que corresponde al predio al que se refiere la rogatoria» (Tribunal Registral, s. f., p. 58).
\end{abstract}

Trámite

- Petición escrita de los interesados ${ }^{3}$, anexando:

- Planos de ubicación y perimétricos, suscritos por un ingeniero o arquitecto colegiado y debidamente visados por la autoridad municipal.

- La prueba testimonial de no menos de tres ni más de seis personas mayores de 25 años, preferentemente vecinos u ocupantes de los inmuebles colindantes del predio cuyo saneamiento se solicita.

- Certificación registral en el sentido de que la nueva área no se superpone con las colindantes (certificado de búsqueda catastral).

- Admitida a trámite la solicitud, se deberá proceder a su anotación preventiva, conforme al artículo 36 del Decreto Supremo n. ${ }^{\circ} 035$ 2006-VIVIENDA.

- En cuanto a los actos procedimentales, es de aplicación supletoria del procedimiento notarial de prescripción adquisitiva también tramitado notarialmente.

- En la fase de calificación registral existen aspectos que no pueden ser objeto de la evaluación por las instancias registrales, dado que jurisprudencialmente se ha establecido que «no será materia de calificación la validez de los actos procedimentales que, en virtud de lo previsto en la Ley No 27333 y normas complementarias, son de competencia del Notario, ni el fondo o motivación de la declaración notarial» (Superintendencia Nacional de los Registros Públicos, 2003, art. 5.2).

3 El notario competente es el de la provincia donde se encuentre ubicado el predio, por lo que carecerá de competencia cualquier notario de una jurisdicción distinta. 
Ventajas $\quad-$ No se requiere presentación de plano catastral o con código único catastral, pero sí de planos visados municipalmente.

- A nivel jurisprudencial se admite la rectificación pese a que el Área de Catastro del Registro de Predios no puede determinar la existencia o inexistencia de superposición.

Desventajas - No existe un procedimiento detallado de su realización, legal o reglamentado, lo que genera diversas interpretaciones jurisprudenciales.

- Podremos encontrar denegatorias de inscripción basadas en superposiciones «insignificantes» o solamente «gráficas» que no superan las tolerancias catastrales.

- Cualquier oposición de terceros, aun sin legitimación comprobada o sustento alguno, pone fin al procedimiento.

- Los informes y las certificaciones catastrales previas al procedimiento no vinculan a futuras verificaciones catastrales en la calificación de su inscripción.

- El registro no ofrece certificaciones registrales sobre los predios colindantes ni su titularidad para permitir la correcta notificación por parte del notario.

- No es aplicable a predios rústicos.

\subsection{Procedimiento registral. Rectificación de área por error de cálculo}

\section{Tabla 6}

\section{Registral. Rectificación de área por error de cálculo}

Origen

Precedente:

XIX Pleno

del Tribunal

Registral
«Es inscribible la rectificación del área de un predio urbano en mérito al plano $y$ memoria descriptiva visados por la autoridad municipal correspondiente, prescindiendo de los mecanismos rectificatorios previstos en el artículo $13^{\circ}$ de la Ley $N^{o} 27333$, si el error surgió del equivocado o inexacto cálculo de su área, siempre que el Área de Catastro determine que los linderos y ubicación espacial del predio no han sufrido variación alguna» (Tribunal Registral, 1999; 2005, p. 1; 2006). 
Presupuestos

Precedente

vinculante

Resolución

del presidente

del Tribunal

Registral

n. ${ }^{\circ} 127-2020-$

SUNARP/PT.

Unificación

de sumillas

de acuerdos y

precedentes de

observancia

obligatoria

sobre

rectificación

de área por

error de cálculo

aprobados en

el Pleno XIX y

precisados en

los plenos CXV

y CLXXIV
- Tiene por objetivo corregir un error cometido cuando se inmatriculó el predio en el registro o en las modificaciones físicas de este derivadas de inscripciones posteriores.

- Si el error surgió de un equivocado o inexacto cálculo matemático del área es inscribible la rectificación del área de un predio urbano en mérito al plano y la memoria descriptiva visados por la autoridad municipal correspondiente, prescindiendo de los mecanismos rectificatorios previstos por el artículo 13 de la Ley $n .^{\circ} 27333$, siempre que en los antecedentes registrales obren las medidas perimétricas y estas se mantengan inalterables.

- También procede la rectificación por error de cálculo respecto de predios rurales, para lo cual se adjuntará la documentación que refiere el artículo 20 del reglamento de inscripciones del registro de predios.

- Se requiere un informe del Área de Catastro que determine que los linderos, las medidas perimétricas y la ubicación espacial del predio no han sufrido variación alguna, en función de la información gráfica con la que se cuenta. Sin embargo, si el Área de Catastro no lo puede determinar por inexistencia de la información gráfica en los antecedentes registrales o por defectos de ella, procederá la rectificación.

Ventajas - Es aplicable a predios urbanos y rurales.

- No se utilizan los procedimientos establecidos en el artículo 13 de la Ley n. ${ }^{\circ} 27333$.

- No requiere intervención ni notificación a los propietarios de los predios colindantes.

- El Área de Catastro del Registro de Predios es la que determina que, a pesar de que el polígono y los linderos del predio son los mismos, su área no corresponde, sin necesidad contar con un plano visado ni código único catastral.

- Procede pese a que el Área de Catastro del Registro de Predios no pueda determinar que el área, los linderos, las medidas perimétricas y la ubicación espacial han sufrido variación alguna.

Desventajas - No permite modificar los linderos y las medidas perimétricas.

- No obstante se verifique la correspondencia con la base gráfica registral, siempre es necesario contar con un plano catastral o visado municipalmente.

- Genera un cierto grado de inseguridad por la falta de notificación a los propietarios de los predios colindantes. 
- Como puede apreciarse, este mecanismo no es propiamente uno de saneamiento de linderos y medidas perimétricas, sino exclusivamente del área registrada, por lo que la variación, aunque sea mínima, de dichos linderos y medidas perimétricas registrados, impedirá su aplicación, pues para lograrlo deberá utilizar el mecanismo de saneamiento jurisprudencial de saneamiento unilateral que estudiaremos en el punto siguiente.

\title{
3.4. Procedimiento registral. Rectificación unilateral
}

\author{
Tabla 7 \\ Registral. Rectificación unilateral de área, linderos y medidas \\ perimétricas (precedente de obseruancia obligatoria del CLV Pleno \\ del Tribunal Registral)
}

Origen

Precedente:

CLV Pleno
- «Procede la rectificación de área, linderos y/o medidas perimétricas en mérito a escritura pública otorgada por el propietario acompañada de la documentación a que se refiere el artículo 20 del Reglamento de Inscripciones del Registro de Predios, solo si el Área de Catastro determina indubitablemente que el ámbito gráfico resultante se encuentra dentro del predio inscrito.

Dicha rectificación no procederá cuando se afecten derechos de acreedores inscritos o medidas cautelares, salvo que los afectados o el órgano jurisdiccional o administrativo autoricen la rectificación» (Tribunal Registral, 2016b, p. 13).

Presupuestos - Aplicación tanto a predios urbanos como rústicos.

- La otorga solo el titular o titulares registrales del predio materia de saneamiento.

- No se requiere la intervención de ningún propietario de los predios colindantes.

- Debe formalizarse por Escritura Pública.

- No implica inspección física del predio ni notificación a los colindantes, tanto por el notario como por el registrador.

- Deben adjuntarse los planos visados por la municipalidad competente o los documentos catastrales emitidos por ella.

- Debe acreditarse, con el informe del Área de Catastro de la SUNARP, que no se presenta superposición ni afectación alguna a predio colindante. 

Ventajas $\quad-$ Es aplicable para predios urbanos y rurales.
- No se aplican los procedimientos establecidos en el artículo 13 de la Ley n. ${ }^{\circ} 27333$.
- No requiere intervención ni notificación a los propietarios de los predios colindantes.
- No requiere inspección física del predio.
- No requiere la participación de todos los copropietarios del predio a rectificar.
- Permite modificar el área del predio (aumentándola o disminuyéndola), y también sus linderos y medidas perimétricas siempre que se determine que no afecte derechos de terceros.
- No procede en caso de que se determine superposición de las áreas, evitando el perjuicio de terceros.

Desventajas - Requiere la presentación de plano catastral o visado por la municipalidad.

- No procede la rectificación si el Área de Catastro del Registro de Predios no puede emitir un informe positivo para proceder a la rectificación unilateral, lo que se origina en defectos de la misma base gráfica registral.

- Genera cierto grado de inseguridad por la falta de notificación a los propietarios de los predios colindantes, más aún cuando pueden modificarse los linderos y las medidas perimétricas y no solo el área.

Comentarios - En muchos casos, la inexistencia o deficiencia de la base gráfica registral impedirá la emisión del informe del Área Técnica Catastral, que permitiría lograr la inscripción del saneamiento rogado. Se ha concluido, y lo reconocen las mismas directivas y jurisprudencias registrales, que, en muchos casos, por falta de documentos gráficos, las graves carencias de la base gráfica registral impedirán, aun usando información literal, determinar la verdadera ubicación espacial de muchos predios inscritos. Se trata del talón de Aquiles de este mecanismo jurisprudencial. Si consigue superarse, se convertiría en el mecanismo de rectificación de mayor importancia y simplicidad para lograr el acceso de la realidad física del predio a la publicidad registral. 


\section{LA RENUNCIA DE ÁREA COMO MEDIO DE SANEAMIENTO DE ÁREA, LINDEROS Y MEDIDAS PERIMÉTRICAS}

La renuncia de área es uno de los tres mecanismos de saneamiento de área, linderos y medidas perimétricas establecidos por vía jurisprudencial, junto con el error de cálculo y la rectificación unilateral.

Existen criterios divididos sobre si la modalidad de «renuncia de área» puede considerarse como un mecanismo de extinción de la propiedad o no. Quienes opinan que no aluden que dichos mecanismos de extinción se encuentran plasmados taxativamente en la ley, y que la renuncia de área no es uno de ellos. Específicamente, en el artículo 968 del CC se precisan las siguientes causales: i) adquisición del bien por otra persona; ii) destrucción o pérdida total o consumo del bien; iii) expropiación; iv) abandono del bien durante veinte años, en cuyo caso pasa el predio al dominio del Estado. Con lo anterior, la renuncia de área no tendría norma legal expresa que la considere como una de las causas de extinción de la propiedad.

Por el contrario - nos sumamos a esta posición-, otros opinan que la renuncia de área sí constituye una renuncia al derecho de propiedad. Es decir, es un supuesto por el cual se extingue el derecho de propiedad. Precisamente por ello, en principio, la renuncia de área no es un medio de rectificación de área, linderos y medidas perimétricas derivado de la discrepancia entre el registro y la realidad física del predio, sino que se origina en la voluntad de los titulares que deciden dar por extinguida su titularidad dominical, y no en las verdaderas características físicas del predio. Si bien el artículo 968 del CC no contempla la renuncia de área como una forma de extinción de la propiedad, este mecanismo podría fundamentarse en el artículo 2, numeral 24, de la Constitución Política, según el cual, en aplicación del principio de libertad 
civil, nadie está obligado a hacer lo que la ley no manda, ni impedido de hacer lo que ella no prohíbe.

\subsection{Origen}

El concepto fue incorporado, inicialmente, a través de la Resolución n. ${ }^{\circ}$ 054-2007-SUNARP-TR-T, al indicar que: «Es inscribible la renuncia de una sección del predio, siempre que el Área de Catastro determine que los linderos y ubicación espacial del predio inscrito no han sufrido variación alguna, salvo por la porción renunciada que se desinscribe» (Tribunal Registral, 2007a, p. 1).

\section{Tabla 8}

\section{Precedente de observancia obligatoria sobre la renuncia de área}

\begin{tabular}{|c|c|c|c|}
\hline $\begin{array}{l}\text { Precedente: } \\
\text { Pleno CIX }\end{array}$ & $\begin{array}{l}\text { Sesión ordinaria, } \\
\text { de modalidad } \\
\text { presencial, } \\
\text { realizada el } 28 \text { y } 29 \\
\text { de agosto de } 2013 \text {. } \\
\text { Publicado en } E l \\
\text { Peruano el } 13 \text { de } \\
\text { septiembre de } 2013 .\end{array}$ & $\begin{array}{l}\text { Extinción de } \\
\text { inscripción } \\
\text { por renuncia } \\
\text { al derecho de } \\
\text { propiedad }\end{array}$ & $\begin{array}{l}\text { «Es inscribible la cancelación de la } \\
\text { inscripción del derecho de propiedad } \\
\text { sobre todo el predio y su consiguiente } \\
\text { desinmatriculación por renuncia de su } \\
\text { titular, siempre que ello no afecte derechos } \\
\text { de terceros» (Tribunal Registral, 2007b, } \\
\text { p. 1). }\end{array}$ \\
\hline
\end{tabular}

En el CIX Pleno del Tribunal Registral se aprobó el precedente de observancia obligatoria referido a la extinción de inscripción por renuncia al derecho de propiedad, en el sentido de que resultaba viable que el propietario de un bien renuncie a su derecho, en tanto se trata de una manifestación del atributo de disposición que asiste a todo propietario.

En tal sentido, Francisco Escajadillo (2018) señala que:

De esta forma, es que el Tribunal Registral (TR) reconoce la eficacia a nivel registral de la renuncia al derecho de propiedad, determinando algunos de sus efectos jurídicos (estrictamente, registrales), 
como lo son: (i) La inscripción de la extinción del dominio; y, (ii) La desinmatriculación del predio, esto último porque el derecho de propiedad es el que sustenta la apertura de una determinada partida registral, por lo que ante la ausencia del mismo se fundamentaría su cierre por «desinmatriculación» (párr. 3).

\subsection{Características de la renuncia de área}

\subsubsection{La no intervención de terceros}

A través de este mecanismo es posible conseguir la reducción del área inscrita sin intervención de ningún colindante o tercero, siempre que el predio materia de rectificación tenga un área menor que la inscrita registralmente.

\subsubsection{El predio propuesto por el interesado (excluyendo el área renunciada) debe hallarse dentro de los linderos del predio de mayor cabida, es decir, del predio original}

En cumplimiento con lo establecido en el precedente CIX, el predio rectificado y el área renunciada deben quedar dentro del polígono contenido en la base gráfica registral. Así, en caso de que cualquiera de tales áreas, vale decir, parte de los linderos y las medidas del predio, no esté dentro del referido polígono, no procederá la renuncia de área. Esto ha sido enunciado expresamente en la Resolución n. ${ }^{\circ}$ 456-2016-SUNARP-TR-T, que aborda la renuncia de área para poder inmatricular un predio, en cuya sumilla se indica:

La renuncia de área implica que el titular prescinde de una parte o porción del predio de su propiedad. Por esta razón, toda renuncia de área debe dar como resultado un predio que siempre estuvo emplazado dentro del polígono del predio matriz. En este orden, si el predio resultante de la renuncia presenta linderos que rebasan al predio primigenio entonces no será admisible este mecanismo para lograr la inmatriculación (Tribunal Registral, 2016c, p. 1). 


\subsubsection{Improcedencia en caso de imposibilidad del pronunciamiento por parte del Área de Catastro}

El Tribunal Registral no ha establecido un criterio uniforme. En algunos pronunciamientos considera que es improcedente la renuncia de área en caso de que a la Oficina de Catastro, bajo cualquier causa, se le imposibilite afirmar que el área resultante de la renuncia se halle dentro del polígono del predio inscrito. Así lo indican algunas resoluciones, como las que enunciamos a continuación:

Si la oficina de catastro, por cualquier razón, no puede afirmar que el área materia de rectificación por renuncia de área se halla dentro del polígono del predio inscrito, no es aplicable dicho mecanismo de rectificación (Tribunal Registral, 2014, p. 1).

No procede la rectificación de área, linderos y/o medidas perimétricas por renuncia de área si la oficina de catastro, por cualquier razón, no puede afirmar que el área resultante de la renuncia se halla dentro del polígono del predio inscrito (Tribunal Registral, 2015, p. 1).

Una posición contraria, según la cual la imposibilidad por parte de la Oficina de Catastro no puede ser impedimento para la inscripción, en consideración a que los costos de la incapacidad del registro no deben ser trasladados a los administrados, puede apreciarse en el acuerdo del CLXXIV Pleno del Tribunal Registral, que señala:

No impide la inscripción de la rectificación o determinación de área, linderos o medidas perimétricas de un predio que la Oficina de Catastro informe que está imposibilitada de establecer que corresponde al predio que se refiere la rogatoria. Esto no es aplicable a la rectificación de área, linderos y medidas perimétricas recogida en el precedente Pleno $155^{\circ}$ (Tribunal Registral, s. f., p. 58). 
Asimismo, el Tribunal Registral (2021) precisa:

En ese sentido, a falta de norma específica que regule los efectos registrales de la renuncia de parte de un predio inscrito cuya área remanente no es factible de ser determinada por el Área de Catastro - como ocurre en el presente caso-, este colegiado concuerda con el apelante en que es válido aplicar idénticos parámetros a los arriba señalados, pues en ambos casos estamos ante supuestos de modificación de las dimensiones físicas de un predio registrado (p. 15).

Como puede apreciarse, sobre este aspecto no existe uniformidad ni predictibilidad sobre las exigencias de la jurisprudencia registral. Es cierto que, para guardar concordancia con los criterios utilizados en otras formas de saneamiento registral, debería aceptarse que las deficiencias del registro de predios en los datos que figuran en su base gráfica registral no deberían ser trasladadas a los interesados ni impedir la inscripción de una renuncia de área. Pero también es cierto que para el caso de la renuncia parcial, puede generar inseguridad a los derechos de los colindantes que el área resultante de la renuncia pueda superponerse a los predios colindantes.

\subsubsection{Visación de la documentación técnica en la renuncia de área}

Partimos por indicar que la finalidad del procedimiento de visación de la documentación técnica, más precisamente de la visación de planos por las municipalidades, consiste en verificar la concordancia entre la realidad física y los planos presentados; y si ello no es posible, la indicación de la imposibilidad material de su atención.

Según podemos verificar, a modo de ejemplo en el portal web de la Municipalidad Distrital de Miraflores, sobre el procedimiento de visación de planos se indica que: 
El servicio de visación de planos es el procedimiento mediante el cual se otorgan planos y memorias descriptivas visadas por el Subgerente de Catastro de la Municipalidad con el fin de realizar trámites ante registros públicos, correspondientes a prescripción adquisitiva de dominio o rectificación de área y linderos (Municipalidad de Miraflores, s. f., p. 1).

Dentro del procedimiento de renuncia de área, la jurisprudencia registral ha establecido que es requisito de procedencia adjuntar la documentación técnica visada por la municipalidad competente, entidad que, como lo hemos indicado anteriormente, cumple la función de verificar la concordancia entre la realidad física y los planos presentados; y respecto de dicha documentación, debe pronunciarse el Área de Catastro Registral sobre si el área materia de rectificación se halla dentro del polígono del predio inscrito o no; o, en su defecto, indicar dicha imposibilidad de verificación.

El Tribunal Registral (2016d) indica que

para inscribir la modificación de las características físicas de un predio por efecto de la renuncia de área debe presentarse la escritura pública otorgada por el titular registral, así como los planos de ubicación y perimétrico del predio _visados por la autoridad competente o suscrita por verificador, según sea el caso-que reflejen su nueva configuración (p. 1).

\subsection{Renuncia de área us. rectificación unilateral}

A fin de establecer si, realmente, la renuncia de área es un mecanismo de saneamiento diferente a los ya enunciados, es necesario efectuar un análisis comparativo entre el mecanismo jurisprudencial de renuncia de área frente a otro mecanismo, también de origen jurisprudencial registral, denominado rectificación unilateral, cuyas características se han descrito en el punto 3.4. 
En efecto, el Tribunal Registral ha consagrado la denominada rectificación unilateral, en la cual la escritura pública que permite el saneamiento de área, linderos y medidas perimétricas solo es otorgada por el titular registral del predio materia de determinación o rectificación, sin la intervención de ningún propietario de los predios colindantes. El sustento de este mecanismo es la rectificación registral en mérito de instrumento fehaciente regulada por el artículo 85 del Texto Único Ordenado del Reglamento General de los Registros Públicos, pero avanzando más allá del simple error de cálculo del área del predio, comprende también los linderos y las medidas perimétricas del mismo, con la diferencia de que en este supuesto, por su mayor entidad modificatoria, debe tenerse la seguridad absoluta de la no afectación de derechos de los titulares de los predios colindantes.

Después de una profusa y contradictoria discusión jurisprudencial respecto de si la rectificación unilateral era aplicable solo cuando se reducía el predio a un área menor o si también era aceptable cuando incrementaba su área, actualmente se encuentra vigente el Precedente de Observancia Obligatoria aprobado por el CLV Pleno del Tribunal Registral, también analizado anteriormente. Al efectuar un análisis comparativo entre las características jurisprudenciales de la renuncia de área y la rectificación unilateral, podemos concluir que coinciden en lo siguiente:

- Aplicación tanto a predios urbanos como rústicos, por no existir distinción legal o jurisprudencial.

- La rectificación o determinación la otorga solo el titular o los titulares registrales del predio materia de saneamiento.

- No se requiere la intervención de ningún propietario de los predios colindantes.

- Debe formalizarse por escritura pública. 
- No implica inspección física del predio ni notificación a los colindantes, tanto por el notario como por el registrador.

- Deben adjuntarse los planos visados por la municipalidad competente o los documentos catastrales emitidos por ella. En el caso de predios rústicos, el plano del órgano catastral agrario o verificador catastral.

- Debe acreditarse, con el informe del Área de Catastro de la SUNARP, que no se presenta superposición ni afectación alguna a predio colindante.

El análisis detallado de los criterios jurisprudenciales que regulan la renuncia de área, frente al saneamiento unilateral, nos permite afirmar que estos dos mecanismos creados por el Tribunal Registral, al no estar previstos en el artículo 13 de la Ley n. ${ }^{\circ} 27333$, a pesar de ser aparentemente autónomos e independientes, de la manera que los ha configurado la jurisprudencia registral, al exigir la presentación de planos visados municipalmente, la renuncia de área parcial, en la práctica, no es más que una modalidad del precedente jurisprudencial de rectificación unilateral para menor área, pero que el Tribunal Registral de la SUNARP ha regulado como un procedimiento diferente.

Veamos ahora de manera comparativa las características que, en nuestro concepto, deberían diferenciar la rectificación unilateral de área, linderos y medidas perimétricas de la renuncia de área:

\section{Tabla 9}

Renuncia de área us. saneamiento unilateral

\begin{tabular}{ll}
\hline \multicolumn{1}{c}{ Renuncia de área } & \multicolumn{1}{c}{ Saneamiento unilateral } \\
\hline - Escritura pública & - Escritura pública \\
\hline - Necesariamente reduce el área & - Para un área menor o mayor \\
\hline - No requiere necesariamente planos visados & $\begin{array}{c}\text { - Requiere planos visados, pues ese es el } \\
\text { instrumento fehaciente que lo sustenta }\end{array}$ \\
\hline
\end{tabular}


- Requiere informe favorable de catastro respecto de que el área renunciada está dentro del área del predio, según la base gráfica registral

- Es producto de la voluntad del titular de extinguir o reducir su derecho de propiedad

- Genera desinmatriculación voluntaria parcial o total
- Requiere informe favorable de catastro sobre no superposición

- Es un modo de concordar la realidad y el registro

- Genera exactitud registral

\subsection{Extinción de la duplicidad de partidas por renuncia al derecho de propiedad}

El Texto Único Ordenado del Reglamento General de los Registros Públicos, aprobado por Resolución n. ${ }^{\circ}$ 126-2012-SUNARP, define a la duplicidad de partidas de esta manera:

Existe duplicidad de partidas cuando se ha abierto más de una partida registral para el mismo bien mueble o inmueble, la misma persona jurídica o natural, o para el mismo elemento que determine la apertura de una partida registral conforme al tercer párrafo del Artículo IV del Título Preliminar de este Reglamento. Se considera también como duplicidad de partidas la existencia de superposición total o parcial de áreas inscritas en partidas registrales correspondientes a distintos predios (SUNARP, 2012, art. 56).

La posibilidad de utilizar la renuncia de área como mecanismo para la eliminación de la superposición de partidas registrales no tiene una previsión en los reglamentos registrales, puesto que, según el mencionado Texto Único Ordenado del Reglamento General de los Registros Públicos (artículos 60 y 62), el procedimiento regulado para «solucionar» la duplicidad o superposición de partidas con inscripciones incompatibles (que son las verdaderamente relevantes) es uno administrativo registral denominado "cierre de partidas", en el que no se elimina la duplicidad, sino que se limita, en caso de que no se formule oposición, al cierre total o parcial de la partida 
de menor antigüedad, quedando aún vigentes ambas inscripciones. Este procedimiento se encuentra a cargo de la Unidad Técnica Registral (antes Gerencia Registral) y no a cargo del registrador ni el Tribunal Registral. Empero, en la práctica, actualmente aceptada por jurisprudencia no vinculante del Tribunal Registral, el mecanismo de renuncia de área total o parcial ha sido y es usualmente utilizado como medio para eliminar superposiciones de partidas registrales.

Esta situación ha sido advertida por Gunther Gonzales (s. f.) cuando afirma:

Sin embargo, en la realidad sociológica no son usuales los actos de renuncia, pues normalmente se utiliza este envoltorio para encubrir o procurarse finalidades jurídicas diferentes. Así ocurre en el caso de la duplicidad de partidas sobre el mismo predio, que muchas veces pretende regularizarse a través de renuncias anómalas o de puro disfraz. Por ejemplo, la Resolución $\mathrm{N}^{\circ} 096-$ 2007-SUNARP-TR-T admite la renuncia de propiedad para «des-inmatricular» una partida registral, pero en realidad el caso trató de una duplicidad de partidas registrales, cada una con un propietario distinto, por lo que la finalidad del acto no era renunciar para atribuir la titularidad al Estado, sino tenía una causa diferente: reconocer que el mejor título no lo tenía el declarante, sino el otro contendiente (p. 3).

Desde otra perspectiva, Sonia Campos (2014), también advierte que pueden existir otras motivaciones de la renuncia de las áreas distintas a concordar la realidad con el registro, al indicar que

en la realidad se presentan numerosos casos donde los lotes habilitados se han visto reducidos por ampliación de vías, y al no inscribirse los actos previos que se requieren para publicitar el área modificada del lote, el propietario opta por formular renuncia sobre la porción en la que, civilmente, ya no ostenta ninguna titularidad. Si bien logra el efecto buscado - excluir el área de la 
partida del titular renunciante-, generamos una inexactitud, pues el área renunciada no debe desinscribirse, sino solo trasladarse al área de la partida matriz de la cual se independizó, en la cual debería incorporarse al área de vías (p. 187).

En la jurisprudencia registral, si bien aún no existen precedentes de observancia obligatoria, el tema de la renuncia de área como medio de eliminación de superposición de partidas registrales se ha admitido, favorablemente, en diversas resoluciones, como las que enunciamos a continuación:

Es inscribible la cancelación de la inscripción del derecho de propiedad sobre todo el predio y su consiguiente desinmatriculación por renuncia de su titular, siempre que ello no afecte derechos de terceros. La renuncia de propiedad de un predio que se superpone a otro da por finalizada la duplicidad de partidas (Tribunal Registral, 2017a, p. 1).

$\mathrm{Y}$ «La renuncia de propiedad de parte de un predio que se superpone a otro da por finalizada la duplicidad de partidas» (Tribunal Registral, 2020, p. 1).

En la revisión del texto de ambas resoluciones, se aprecia que la aceptación de la renuncia de área como mecanismo de «finalización» de la duplicidad de partidas se ha sustentado en que el Tribunal Registral, ante la ausencia de normatividad expresa, consideró necesario utilizar el criterio doctrinal que sustenta el artículo 313.2 del Reglamento Hipotecario Español, que prevé que en la doble inmatriculación esta cesará y se cancelará si existe acuerdo entre todos los interesados.

Esta línea de pensamiento es expresada en la Resolución n. ${ }^{\circ}$ 266-2017-SUNARP-TR-L, bajo el siguiente fundamento: 
Como podrá apreciarse la normatividad registral prevé que es una autoridad administrativa la que está a cargo del procedimiento de cierre por duplicidad de partidas. Nuestro sistema registral no prevé que las duplicidades de partidas pueden ser solucionadas por todos los interesados, como sí lo ha previsto el artículo 313.2 del Reglamento Hipotecario español:

[...]

2da. Si la doble inmatriculación lo fuere a favor de personas distintas y existiere acuerdo entre ellas, a solicitud suya y con la conformidad de todos los interesados expresada en la escritura pública, se procederá a cancelar o rectificar el folio convenido.

No obstante, consideramos que dado que la jurisprudencia registral peruana acogió el criterio de considerar como acto inscribible la extinción de inscripción por renuncia de propiedad, el criterio legislativo asumido por el Reglamento Hipotecario español es totalmente aplicable en nuestro sistema (Tribunal Registral, 2017b, p. 8).

Personalmente, consideramos que no era necesario acudir a la doctrina española (y menos a un derecho extranjero) para que el Tribunal Registral concluyera que la renuncia de un área que se superpone con otra pone fin a la duplicidad de inscripciones. Si ya había admitido que la renuncia de área genera «desinmatriculación» del área renunciada, es un criterio de lógica básico que si se elimina el supuesto material que da lugar a la superposición de partidas, eso da por concluida esta, aunque ello no esté expresamente previsto en nuestra normatividad registral (al igual que la propia renuncia de área). 


\subsection{Ventajas y desuentajas de la renuncia de área}

\section{Tabla 10}

\section{Ventajas y desuentajas de la renuncia de área}

\section{Ventajas}

- Es aplicable para predios urbanos y rurales.

- No se aplican los procedimientos establecidos en el artículo 13 de la Ley n. ${ }^{\circ} 27333$.

- No requiere intervención ni notificación a los propietarios de los predios colindantes.

- No requiere inspección del predio ni notificación a los colindantes.

- Permite modificar el área del predio disminuyéndola, pero el predio resultante y el área renunciada deben quedar dentro del polígono ya registrado.

- No procede en caso de que se determine superposición de las áreas, evitando el perjuicio de terceros.

- Solo se deben presentar planos y memoria descriptiva visados por la municipalidad respecto del predio resultante tras la renuncia, no es necesaria la exigencia del Código Único Catastral.

\section{Desventajas}

- Esta rectificación es innecesaria, pues el mismo propósito se logra con la rectificación unilateral, con los mismos requisitos. En verdad, actualmente es solo una modalidad de esta.

- Esta rectificación es de dudosa jerarquía legislativa frente a lo regulado por el CC, pues no se sabe si el área renunciada sería adquirida por el Estado o si se estaría generando una res nullius.

- No procede la rectificación si el Área de Catastro del Registro de Predios no puede emitir informe positivo respecto de la ubicación del área de renuncia como respecto de superposiciones en el área remanente.

\section{ESTADÍSTICAS SOBRE LA EFICIENCIA DE LA RENUNCIA DE ÁREA EN LAS RESOLUCIONES DEL TRIBUNAL REGISTRAL. PERÍODO 2014-2018}

Como referente, para apreciar la eficiencia para lograr la inscripción, en la segunda y última instancia registral del procedimiento de renuncia de área, se procedió a analizar las resoluciones emitidas por el Tribunal Registral durante el período 2014-2018, encontradas y recopiladas de forma directa en la página web https://www. sunarp.gob.pe/busqueda/index.asp, relacionadas a continuación: 


\section{Tabla 11}

\section{Relación de resoluciones de renuncia de área (2014 a 2018)}

\begin{tabular}{|c|c|c|c|}
\hline & Resolución & Año & Solicitud \\
\hline 1 & 137-2014-SUNARP-TR-T & 2014 & $\begin{array}{l}\text { Inscripción de compraventa/renuncia de } \\
\text { área }\end{array}$ \\
\hline 2 & 439-2014-SUNARP-TR-L & 2014 & Inscripción de renuncia de área \\
\hline 3 & 1550-2014-SUNARP-TR-L & 2014 & Inscripción de renuncia de área \\
\hline 4 & 060-2015-SUNARP-TR-T & 2015 & Inmatriculación/renuncia de área \\
\hline 5 & 892-2015-SUNARP-TR-L & 2015 & Inscripción de renuncia de área \\
\hline 6 & 1168-2015-SUNARP-TR-L & 2015 & Rectificación por renuncia de área \\
\hline 7 & 2350-2015-SUNARP-TR-L & 2015 & Inmatriculación/renuncia de área \\
\hline 8 & 010-2016-SUNARP-TR-T & 2016 & Inscripción de renuncia de área \\
\hline 9 & 456-2016-SUNARP-TR-T & 2016 & Inmatriculación/renuncia de área \\
\hline 10 & 466-2016-SUNARP-TR-T & 2016 & Inmatriculación/renuncia de área \\
\hline 11 & 964-2016-SUNARP-TR-L & 2016 & Inmatriculación/renuncia de área \\
\hline 12 & 377-2017-SUNARP-TR-T & 2017 & $\begin{array}{c}\text { Acumulación y renuncia de área de mayor } \\
\text { extensión }\end{array}$ \\
\hline 13 & 473-2017-SUNARP-TR-L & 2017 & Inscripción de renuncia de área \\
\hline 14 & 2207-2017-SUNARP-TR-L & 2017 & Inscripción de renuncia de área \\
\hline
\end{tabular}

Respecto del análisis de contenidos de las resoluciones del Tribunal Registral, en cuanto al resultado de las apelaciones por denegatorias de inscripción de actos de renuncia de área, hemos procesado la siguiente información: 
Tabla 12

\section{Calificación del Tribunal Registral}

a) Revoca la observación y dispone la inscripción

b) Revoca parcialmente la observación y no dispone inscribir

c) Confirma la observación

d) Confirma la tacha

e) Revoca la observación y dispone la tacha

TOTAL

Fuente: https://www.sunarp.gob.pe/busqueda/index.asp

En gráficos porcentuales, tenemos:

\section{Gráfico 3}

\section{Renuncia de área}

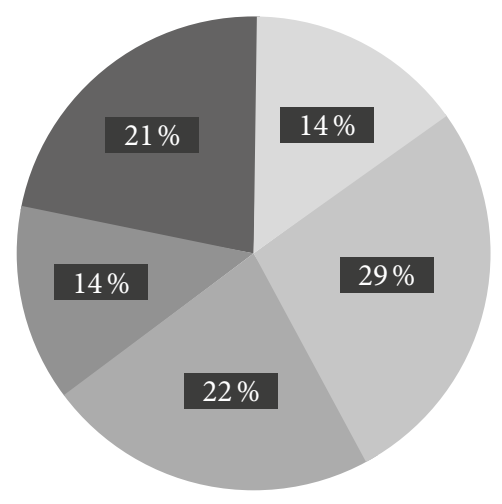

a) Revoca la observación y dispone la inscripción

b) Revoca parcialmente la observación y no dispone inscribir

c) Confirma la observación

d) Confirma la tacha

e) Revoca la observación y dispone la tacha

Consolidando los posibles resultados de los pronunciamientos del Tribunal Registral en solo dos indicadores, es decir, si se dispone la inscripción del saneamiento o no, arribamos al siguiente resultado: 
Tabla 13

¿Se logra la rectificación por renuncia de área?

\begin{tabular}{|c|c|c|c|}
\hline & Sí & No & Total \\
\hline Renuncia de área & 2 & 12 & $\mathbf{1 4}$ \\
\hline
\end{tabular}

Fuente: https://www.sunarp.gob.pe/busqueda/index.asp

\section{Gráfico 4}

\section{Registral renuncia de área}

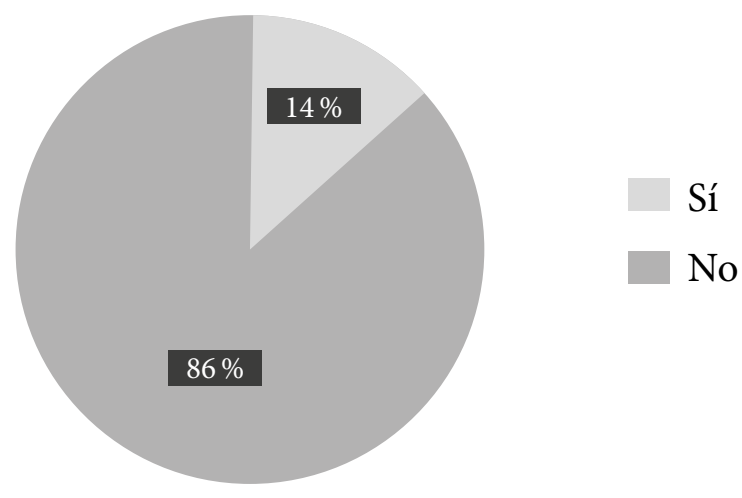

De lo analizado, podemos concluir que del $100 \%$ de recursos de apelación formulados ante el Tribunal Registral en el período de estudio (2014-2018), solo el 14 \% de los casos de renuncia de área lograron que el citado tribunal disponga su inscripción.

Esta información, en la que el $86 \%$ de las apelaciones planteadas respecto de la denegatoria de inscripción de renuncia de área no logra la inscripción solicitada, solo confirma que los problemas en su regulación, las deficiencias del propio registro y la falta de claridad en los pronunciamientos jurisprudenciales han generado que la gran mayoría de pedidos sean denegados por la segunda instancia registral. No se cuenta con el detalle porcentual de las inscripciones en relación con títulos presentados en la primera 
instancia registral (registrador público), en la medida que la SUNARP no cuenta con dicha información. Sin embargo, lo que ocurre en la segunda y última instancia registral, normalmente más orientada a corregir los excesos en las denegatorias de inscripción emitidas por los registradores, no demuestra lo difícil que es inscribir este tipo de saneamiento en el Registro de Predios. Todo ello amerita plantear mejoras tanto normativas como operativas en este mecanismo de saneamiento, que nos demuestra que las soluciones meramente basadas en la jurisprudencia administrativo-registral, a pesar de tener una correcta orientación para generar mecanismos extrajudiciales de saneamiento, en la práctica no logran una verdadera eficiencia en sus resultados.

\section{CONCLUSIONES}

1. El saneamiento de áreas, linderos y medidas perimétricas de predios urbanos puede efectuarse mediante distintos tipos de procedimientos: en la vía judicial o, alternativamente, a través de medios registrales y notariales.

2. El procedimiento judicial de rectificación de áreas, linderos y medidas perimétricas, si bien por su mayor alcance y ámbito de aplicación puede resolver la generalidad de casos, debido a la excesiva demora en su tramitación, así como la limitación para el logro de pronunciamientos definitivos favorables al saneamiento, no constituye una alternativa que brinde una respuesta satisfactoria y eficiente para solucionar las muy frecuentes discrepancias entre las características físicas de los predios que aparecen en el registro frente a las existentes en la realidad.

3. Si bien ha sido positivo que se establezcan, a través del artículo 13 de la Ley n. ${ }^{\circ}$ 27333, dos medios notariales de saneamiento de área, linderos y medidas perimétricas de predios urbanos, como la escritura pública de mutuo acuerdo y el asunto no 
contencioso de competencia notarial, a través de muchos pronunciamientos emitidos por la jurisprudencia registral, se aprecia que tienen graves deficiencias que limitan su aplicación generalizada, no obstante la intención del legislador de establecer medios extrajudiciales de fácil uso por los administrados.

4. El Tribunal Registral de la SUNARP, ante las dificultades en la aplicación de los mecanismos de saneamiento de área, linderos y medidas perimétricas notariales y la carencia de un verdadero catastro, ha establecido diversos precedentes de observancia obligatoria, generando nuevos mecanismos de saneamiento como el de corrección por «error de cálculo», «rectificación unilateral» y «renuncia de área», que si bien tienen una orientación favorable para el fin propuesto, constituyen supuestos parcialmente eficientes, orientados a casos específicos e, inclusive, sujetos a criterios contradictorios en la misma jurisprudencia registral.

5. Específicamente, respecto del mecanismo jurisprudencial denominado renuncia de área, consideramos que, por la forma desarrollada actualmente por los precedentes de observancia obligatoria, es un criterio jurisprudencial innecesario, pues los mismos efectos pueden lograrse con la aplicación de la denominada rectificación unilateral a área menor, que está debidamente regulada por el Precedente del CLV Pleno del Tribunal Registral. Además, se ha probado que su uso en la práctica jurisprudencial registral alcanza escasos niveles de eficiencia para lograr la inscripción del saneamiento de áreas, linderos y medidas perimétricas que se aspira conseguir.

6. De otro lado, respecto de la misma renuncia de área, debemos destacar que, además de estar sujeta a cuestionamientos a su legalidad, por no estar expresamente regulada por el CC, genera la interrogante respecto de si el área renunciada sería adquirida (sin saberlo) por el Estado o que se estaría generando una 
res nullius (bien predial sin titularidad alguna), que tampoco está prevista en nuestra legislación civil sustantiva.

7. Estimamos que la única razón para mantener este mecanismo de renuncia de área sería orientarlo a una nueva utilidad práctica: el reconocimiento de la titularidad que efectúa un propietario de un predio inscrito respecto del de otro con el cual presenta superposición, para lograr eliminar las numerosas duplicidades o superposiciones de partidas existentes en el Registro de Predios, sin tener que acudir a largos y complicados procesos judiciales.

8. Finalmente, atendiendo a las evidentes limitaciones operativas, los supuestos contradictorios y la carencia de regulación normativa (en el caso de los mecanismos jurisprudenciales), resulta necesario que a través de una norma legal específica se unifiquen y armonicen todos los supuestos, requisitos y efectos de los medios notariales y registrales de saneamiento de áreas, linderos y medidas perimétricas de predios urbanos, para que obtengan un mayor grado de predictibilidad y eficiencia.

\section{REFERENCIAS}

Banco Mundial (2020). Doing Business en el Perú 2020. Banco Internacional para la Reconstrucción y el Desarrollo/Banco Mundial.

Becerra, H. P., Samillan, A. R. y Esquivel, L. D. (2019). La rectificación de área, linderos y medidas perimétricas en la legislación peruana. Instituto Pacífico.

Campos, S. (2014) Rectificación y/o determinación de área, linderos y medidas perimétricas de predios en la jurisprudencia registral. Fuero Registral, (12), 167-207. https://scr.sunarp.gob.pe/ repositorio/publicaciones/revista-fuero-registral/2014/FUERO -REGISTRAL-112014.pdf 
Código Procesal Civil (1993). Resolución Ministerial n. ${ }^{\circ}$ 010-93JUS. Perú: 8 de enero de 1993.

Congreso de la República (2000). Ley n. ${ }^{\circ} 27333$. Ley complementaria a la Ley n. ${ }^{\circ}$ 26662, Ley de Asuntos No Contensiosos de Competencia Notarial, para la Regularización de Edificaciones. Lima: 30 de julio de 2000.

Corte Suprema de Justicia de la República (2018). Expediente n. ${ }^{\circ}$ 28883-2018-0-5001-SU-DC-01. Sala de Derecho Constitucional y Social Permanente. Lima: 6 de diciembre de 2018. https://apps.pj.gob.pe/cejSupremo/Expediente/DetalleExpediente. aspx?data=EDcGOhqO0FCBIbVE0tOGMmG7c8RUhvUC7pt wUaeL51G0uuaLootuVGI\%2fZAFQwknsZibHCPAAR2x7ZR 64CsQ2q2D1yXvvSgygG\%2ffuMAf5vgk6eV3EjyJWOP7Iv\% 2fkh1Ov\%2bkhKSHWrp9CVxdtlx51WwuxzHesRw\%2bumllY HS\%2boOZmT58Bgom1B\%2fdHh5hUH8n\%2fS0nkWRxP6 OPovcmD7vnVvt06WLl1RkwgWpUZiewDABdybiD

Escajadillo, F. (2018, 23 de octubre). Más allá de los efectos (meramente) registrales de la renuncia al derecho de propiedad. Portal jurídico IUS $360^{\circ}$. https://ius360.com/mas-alla-de-losefectos-meramente-registrales-de-la-renuncia-al-derecho-depropiedad/

Gaceta Jurídica (2015). La justicia en el Perú. Cinco grandes problemas. Documento preliminar 2014-2015. Gaceta Jurídica.

Gaceta Jurídica (2021, 6 de enero). Fijan el valor de la Unidad de Referencia Procesal (URP) para el año 2021. http://gacetajuridica. com.pe/detalle_noti.php?in=OT0005090\#: :text=Sobre\%20 el\%20particular\%2C\%20se\%20fija,\%C2\%B0\%20392\%2D20 $20 \% 2 \mathrm{D} \% 20 \mathrm{EF}$

Gonzales, G. H. (2002). Tratado de Derecho Registral Inmobiliario. Jurista Editores. 
Gonzales, G. H. (s. f.). Sobre la renuncia de la propiedad. https:// www.usmp.edu.pe/derecho/10ciclo/civil/seminario_derecho_ registral/dr_amado/art_nac/RENUNCIA\%20A\%20LA\%20 PROPIEDAD.pdf

Guerra, R. (2014). La función económica del predio y la necesidad de lograr la convergencia de la realidad física con el Registro. Gaceta Civil \& Procesal Civil, (16), 339-355.

Municipalidad de Miraflores (s. f.). Visación de planos. http://www. miraflores.gob.pe/Gestorw3b/files/pdf/8977-17662-visacion.pdf

Silva, F. L. (2009). Rectificación de área, linderos y medidas perimétricas de un predio por mutuo acuerdo. Diálogo con la Jurisprudencia, (127), 277-282.

Superintendencia Nacional de los Registros Públicos (SUNARP) (2003). Directiva n. ${ }^{\circ}$ 013-2003-SUNARP/SN.

Superintendencia Nacional de los Registros Públicos (SUNARP) (2012). Resolución n. ${ }^{\circ}$ 126-2012-SUNARP-SN.

Tribunal Registral (1999). Resolución n. ${ }^{\circ}$ 290-99-ORLC-TR. 5 de noviembre de 1999.

Tribunal Registral (2005). Resolución n. ${ }^{0}$ 182-2005-SUNARP-TR-T. Trujillo: 28 de octubre de 2005.

Tribunal Registral (2006). Resolución n. ${ }^{\circ}$ 062-2006-SUNARP-TR-L. Lima: 31 de enero de 2006.

Tribunal Registral (2007a). Resolución n. ${ }^{\circ}$ 054-2007-SUNARP-TR-T. Trujillo: 12 de marzo de 2007.

Tribunal Registral (2007b). Resolución n. ${ }^{\circ}$ 096-2007-SUNARP-TR-T. Trujillo: 2 de mayo de 2007.

Tribunal Registral (2007c). Resolución n. ${ }^{\circ}$ 324-2007-SUNARP-TR-T. Trujillo: 19 de diciembre de 2007. 
Tribunal Registral (2013). Resolución n. ${ }^{\circ}$ 329-2013-SUNARP-TR-A. Arequipa: 18 de julio de 2013.

Tribunal Registral (2014). Resolución n. ${ }^{\circ}$ 439-2014-SUNARP-TR-L. Lima: 6 de marzo de 2014.

Tribunal Registral (2015). Resolución n. ${ }^{\circ}$ 1168-2015-SUNARP-TR-L. Lima: 15 de junio de 2015.

Tribunal Registral (2016a). Resolución n. ${ }^{\circ}$ 024-2016-SUNARP-TR-T. Trujillo: 14 de enero de 2016.

Tribunal Registral (2016b). Resolución n. ${ }^{\circ}$ 1622-2016-SUNARP-TR-L. Lima: 16 de agosto de 2016.

Tribunal Registral (2016c). Resolución n. ${ }^{\circ}$ 456-2016-SUNARP-TR-T. Trujillo: 18 de octubre de 2016.

Tribunal Registral (2016d). Resolución n. ${ }^{\circ}$ 560-2016-SUNARP-TR-T. Trujillo: 26 de diciembre de 2016.

Tribunal Registral (2017a). Resolución n. ${ }^{\circ}$ 266-2017-SUNARP-TR-L. Lima: 6 de febrero de 2017.

Tribunal Registral (2017b). Resolución n. ${ }^{\circ}$ 317-2017-SUNARP-TR-T. Trujillo: 24 de julio de 2017.

Tribunal Registral (2020). Resolución n. ${ }^{\circ}$ 1359-2020-SUNARP-TR-L. Lima: 10 de agosto de 2020.

Tribunal Registral (2021). Resolución n. ${ }^{\circ}$ 099-2021-SUNARP-TR-L. Lima: 15 de enero de 2021.

Tribunal Registral (s. f.). Acuerdos Plenarios. https://www.sunarp. gob.pe/tribunalRegistral/AcuerdosactualizadosalCLXXII.pdf 